\title{
Perioral rejuvenation: restoration of attractiveness in aging females by minimally invasive procedures
}

This article was published in the following Dove Press journal:

Clinical Interventions in Aging

30 August 2013

Number of times this article has been viewed

\section{Uwe Wollina}

Department of Dermatology and Allergology, Academic Teaching Hospital Dresden-Friedrichstadt, Dresden, Germany
Correspondence: Uwe Wollina Department of Dermatology and Allergology, Academic Teaching Hospital Dresden-Friedrichstadt, Friedrichstrasse 4I, 01067 Dresden, Germany

$\mathrm{Tel}+4935 \mathrm{I} 4801685$

Fax +49 35I 480I2I9

E-mail wollina-uw@khdf.de
Abstract: Lips and the perioral area are of outstanding importance in youthful appearance, attractiveness, and beauty. In contrast to younger and middle aged females, there is only scant published data on minimally invasive procedures to restore and revitalize lips and perioral soft tissue in elderly females. In this review we report the signs of aging in this particular region and the underlying anatomy. We review studies on lip restoration in younger females and present our techniques for elderly women. With an individually tailored approach, elderly females benefit from minimally invasive techniques.

Keywords: facial aging, perioral soft tissue, lips, dermal fillers, anatomy

\section{Introduction}

Lips are a central part of facial aesthetics due to their color, surface texture, and shape. Well defined and full lips represent attractiveness and beauty. Loss of volume and elasticity of subcutaneous soft tissue, retraction of lip red, bone resorption, loss of teeth, smoking, and ultraviolet exposure contribute to perioral aging and loss of attractiveness. Furthermore, lips are exposed to irritants and environmental factors that challenge the barrier function of their thin horny layer. The lips are conceived as signs of aging, loss of attractiveness, and fragility. ${ }^{1}$

Lips are part of the aesthetic unit that involves the mouth and the perioral tissue. Aging of this area is characterized by perioral fine lines, marionette lines, and flattening of the cupid bow. The philtrum becomes longer and ill defined, indirectly contributing to a thinner upper lip. ${ }^{2}$ Furthermore, the dynamics of lip movement change with age. The smile, for instance, gets narrower vertically and wider transversely. People older than 50 years of age lose their ability of a high smile. ${ }^{3}$

Skin and lip care may help to preserve a youthful and healthy appearance. ${ }^{4,5}$ Dentistry plays a significant role in restoring perioral and mouth aesthetics, not only in elderly people. ${ }^{6}$ Restorative techniques of the perioral soft tissue will further enhance the aesthetic outcome of aesthetic restorative dentistry. ${ }^{7}$

In our review, we will focus on minimally invasive procedures such as dermal filler injection and botulinum toxin A application in women 50 years of age and older. All procedures need a detailed knowledge of anatomy, pharmacology, and technical skills to be safe for patients. The usual medical background is dermatology or plastic surgery. Although the legal situation can vary between countries, attendance of certified courses and workshops by medical societies is highly recommended. This does not, however, replace personal technical skills. 


\section{Anatomy}

The mandible, maxillary bone, and teeth represent the hard tissue structures that will shape the perioral area and the mouth (Figure 1). Aging affects these structures. Maxillary retrusion of the maxilla is evident in both fully dentated patients and those with loss of teeth. Deepening of the maxilla supports a posterior positioning of the upper lip and the nasolabial fold. ${ }^{8}$ Three dimensional computed tomography (CT) demonstrated that mandibular height and length decrease with age. ${ }^{9}$

The perioral muscles are arranged in several layers. The orbicularis oris muscle interlaces with perioral muscles, influencing the dynamic actions during speech, smiling, and whistling. On the apical area, fibers of the levator labii superioris insert into the upper lip and the oral sphincter. Laterally, the levator anguli oris and both zygomaticus muscles insert into the upper lip. The risorius muscle and depressor anguli oris insert into the corner of the mouth. The depressor anguli oris is the most superficial mimetic muscle. The lower lip is inserted by the depressor labii inferioris and mentalis, with mentalis also inserting into chin dermis. Both interlace with platysma fibers. Perioral muscles have a different nerve supply from the zygomatic and buccal branches of the facial nerve (zygomaticus, levator anguli oris, levator labii superioris, and part of orbicularis oris), and marginal branches of the facial nerve (part of orbicularis oris, depressor anguli oris, mentalis). ${ }^{10}$

Superficial fat compartments are arranged in the perioral area. The jowl compartment above the mandible and the nasolabial compartment can influence the lateral upper lip and the corners of the mouth. ${ }^{11}$ Facial fat is divided into deep and superficial planes. The perioral fat is characterized by a deep department beneath mentalis and orbicularis oris muscles different from small lobuled superficial fat of the lips. The wet-dry transition zone of the lips defines the most anterior border of the submuscular deep fat tissue. ${ }^{12}$ Cadaveric studies ${ }^{13}$ of perioral soft tissue demonstrated a lipomatous area without defined ligamentous attachment. The perioral mound with a scaffold of fine trabecular fibrouse separations defines a separate fat pad compartment. With aging it becomes lipodystrophic and ptotic. ${ }^{13}$

Deep fat depots have been defined under the melomental (marionette) line. Since these depots are surrounded by retaining ligaments (condensations of fibrous tissue), this may affect volumizing procedures. ${ }^{14}$ The philtrum is characterized by a fat compartmentation by delicate membranes related to its particular vascular anatomy. ${ }^{15}$
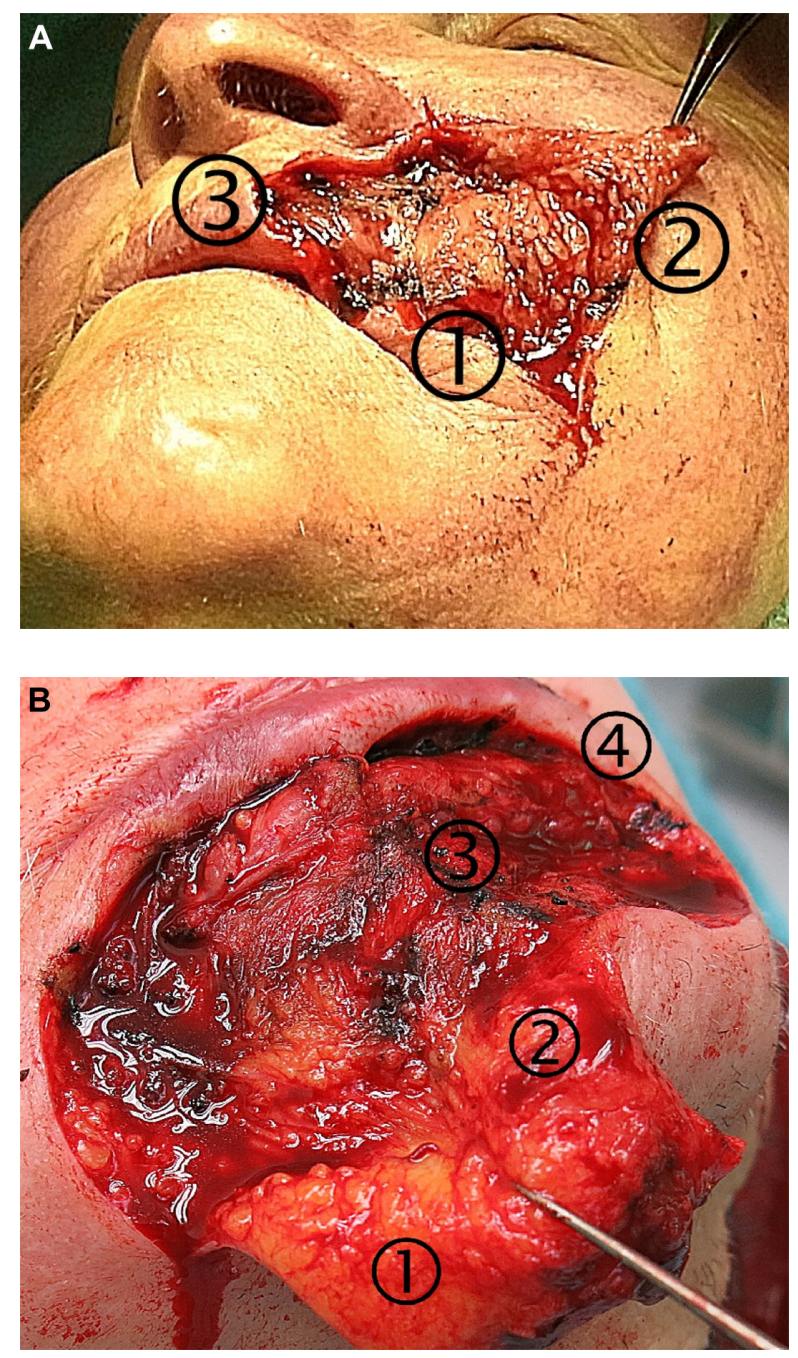

Figure I Anatomy of upper and lower lip region.

Notes: (A) Upper lip showing (I) the nasolabial deep fat pad, (2) the superficial fat layer with delicate small lobules, and (3) collumella of the philtrum. (B) Lower lip showing ( 1 ) the superficial fat layer with larger lobules than in the midface, (2) the deep fat pad between mentalis muscle branches, (3) orbicularis oris muscle and (4) the lower lip with small lobules of superficial fat.

Sensory innervation of the perioral skin arises from infraorbital nerve branches (upper lip and philtrum), the buccal nerve (corners of the mouth), and the mental nerve (lower lip and chin). ${ }^{10}$

\section{Grading scales for perioral lines and lip fullness}

There is no doubt about the need for validated grading scales to measure effects of aging and objective evaluations of therapeutic trials. A validated 5-point photonumeric lip scale, the lip fullness scale (LFS) has been developed by Carutthers et al. ${ }^{16}$ Separate grading for upper and lower lips is recommended. The scale ratings are: very thin (0), thin (1), moderately thick (2), thick (3), and full (4). ${ }^{16}$ 

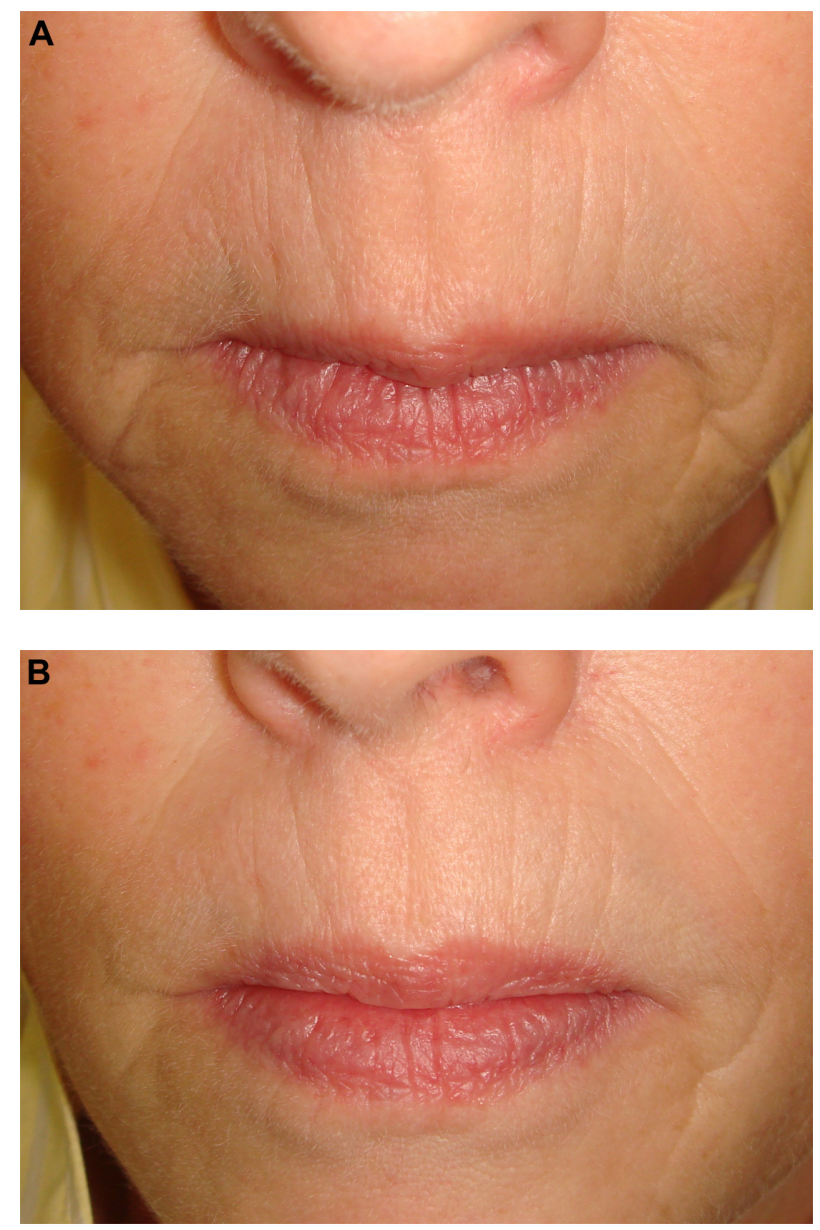

Figure 2 A 55-year-old woman with thin lips and perioral fine lines and elongation of the philtrum.

Notes: (A) Before treatment lip fullness scale (LFS) 0 (upper lip) and I (lower lip); marionette line grading scale I. (B) After liquid lift for the cheeks with $2 \mathrm{~mL}$ Juvederm voluma, the perioral region has been remarkably improved. The marionette lines smoothened and the upper lip LFS increased by I scoring grade. The whole perioral area remained untouched by the filler. This example underlines the importance of the nasolabial fat pad for upper lip aesthetics.

The same group of international experts developed a validated grading scale for melomental folds (marionette lines), the marionette line grading scale. ${ }^{17}$ The 5 -point photonumeric scale differentiates no visible folds (0), visible fold with slight indentation (1), moderately deep folds not visible when skin is stretched (2), very long and deep folds (3), and extremely long and deep folds (4). ${ }^{17}$

A limitation of both grading systems is that they do not address dynamic movements of the area. This is of utmost importance in normal life. There are more grading systems for the perioral area available but a detailed discussion is not the focus of this review. ${ }^{15,16}$

\section{Dermal fillers}

Dermal fillers can be subdivided into temporary and permanent fillers. In this article, we will focus on temporary
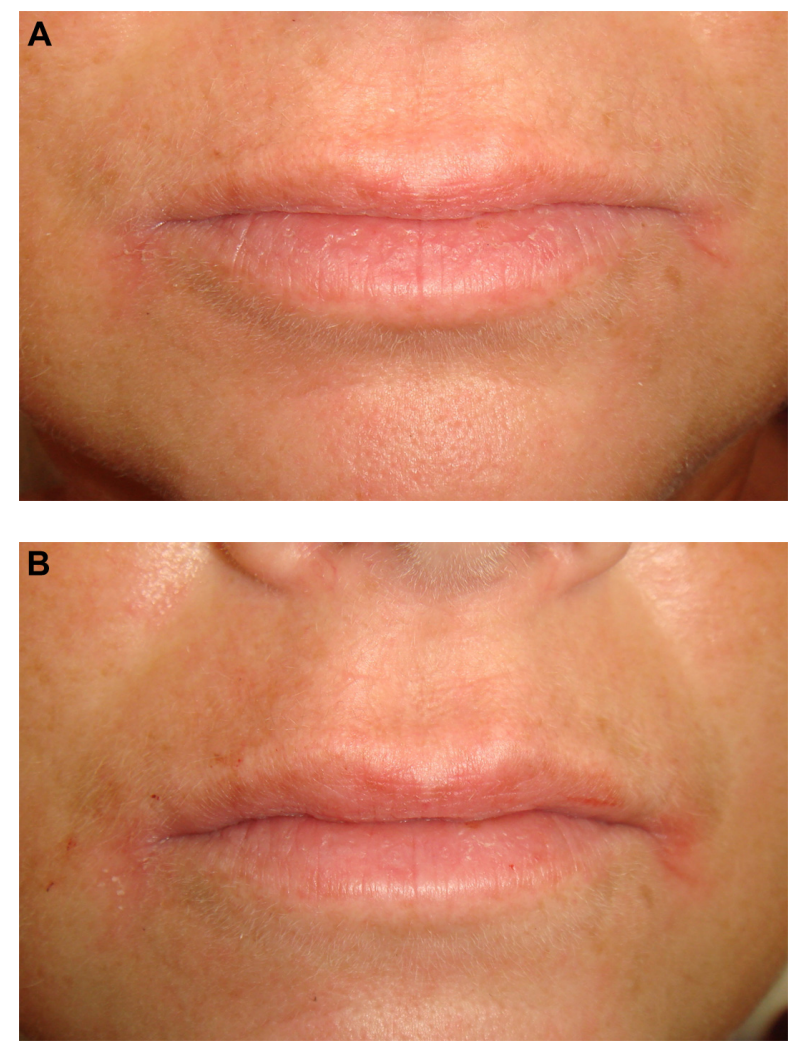

Figure 3 A 45-year-old woman with thin lips and flat philtrum.

Notes: (A) Before treatment lip fullness scale 0 (upper lip) and I (lower lip); marionette line grading scale 0 . (B) Volume restoration of philtrum collumelas and vermillion border by I $\mathrm{mL}$ Juverderm ultrasmile; lip fullness scale I (upper lip).

fillers based on crosslinked hyaluronic acid (HA) fillers. This filler type consists of biphasic (particulate) and monophasic fillers (gel only). ${ }^{17}$

The injection technique is dependent on the filler, area to inject, and the physician and patient preference. To reduce injection and filling related pain, topical anesthetics or nerve blocks may be used. Some fillers contain lidocain to reduce injection pain. It is possible to use either a multiple puncture technique or a threading technique. The latter needs a lesser number of needle sticks. Filling can be performed retrograde or anterograde. Needle diameter is dependent on the choice of filler. For many HA fillers, 27-30 gauge needles are used. Some investigators prefer cannulas. The injections should be done with a slow motion to reduce pain, bruising, and risk of irregularities. Cold compresses before and after the procedure increase comfort and reduce swelling and tenderness. For lip augmentation the HA filler is often placed near the border of the wet and dry lip. Bleeding, nodule formation, and temporary edema are the most frequent adverse effects. ${ }^{18}$ Overcorrections and nodules can easily be corrected by injection of hyaluronidase, a big advantage compared to other filler materials. ${ }^{19}$ 

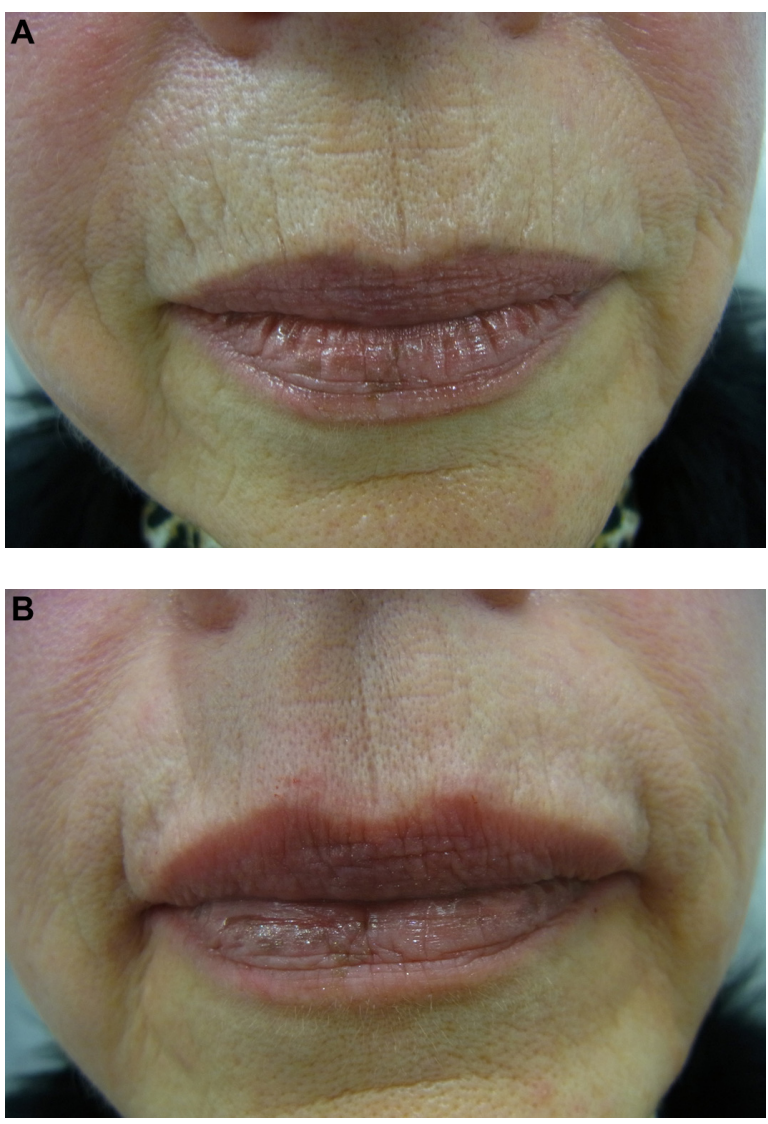

Figure 4 A 67-year-old woman with perioral fine lines and flattening of philtrum collumelas.

Notes: (A) Before treatment lip fullness scale 2 and marionette line grading scale 2 . (B) After restoration of collumellas and volumizing of the white roll (upper lip) along the vermillion border with $2 \mathrm{~mL}$ Juvederm ultrasmile, lip fullness scale 4 (upper lip), marionette line grading scale I. There is improvement of fine lines as well.

Nonaminal stabilized HA ([NASHA] Restylane, Q-Med AB, Uppsala, Sweden) represents a particulate filler type. Restylane Perlane (Q-Med) consists of 10,000 particles/mL. Juvederm (Allergan Inc, Irvine, CA, USA), Belotero (Merz Pharma GmbH and Co, Frankfurt, Germany), Glythone (Pierre Fabre, France and Merz Pharma GmbH and Co), or Teosyal (Teoxane SA, Geneva) are monophasic fillers. Fillers also differ by HA concentration, crosslinking technology, and rheological properties. ${ }^{18,20}$

In an open trial, ${ }^{21} 50$ female subjects were treated with a monophasic HA filler (Juverderm Ultra, Allergan Inc) for lip enhancement. Improvement was measured by the LFS. The mean injected volume was $1.6 \mathrm{~mL}$. More than $90 \%$ of investigators and subjects were satisfied with the results. At week $12,71 \%$ of subjects had an improvement of $\geq 1$ grade on the LFS. Twelve weeks later, lip improvement was still present for $56 \%$ of subjects. ${ }^{21}$

In a multicenter European trial, ${ }^{22} 60$ subjects were treated with the HA filler Juvederm Vobella (Allergan). This new
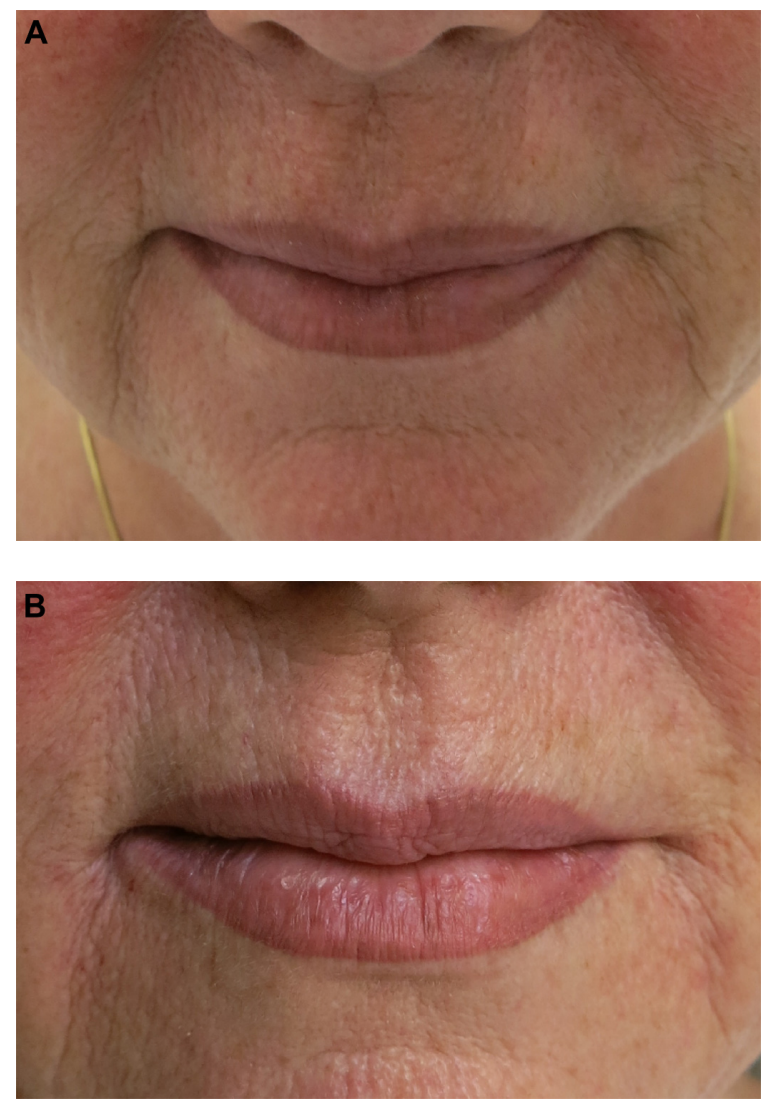

Figure 5 A 60-year-old woman with flattening of Cupid's bow and downward turn of the commissures.

Notes: (A) Before treatment lip fullness scale I for upper lip and 2 for lower lip; marionette line grading scale 2 (left side) and 3 (right side). (B) Volume restoration of philtrum collumelas, a small amount of filler was injected along the vermillion border of the upper lip and volumizing the lateral lower lip. There is smoothening of asymmetries of the perioral area and hyaluronic acid filler $2 \mathrm{~mL}$ Belotero basic was used.

filler is based on a new technology called Vycross. Here, incorporation of short chain and long chain HA is used to enhance crosslinking without increasing stiffness. The Juvederm Vobella filler has an elastic modulus, $\mathrm{G}^{\prime}$, of about $160 \mathrm{~Pa}$, which is lower when compared to other fillers like Juvederm Ultra or Restylane. This creates a smooth soft gel of $15 \mathrm{mg} \mathrm{HA} / \mathrm{mL}$. The mean injected volume was $1.2 \mathrm{~mL}$. The improvement of $\geq 1$ grade in the LFS was reported for $98.3 \%$ of subjects at 3 months and $48.3 \%$ of subjects at 12 months. $^{22}$

In two studies using biphasic, NASHA Restylane (Q-Med) covering 180 subjects and 1,446 subjects, subject satisfaction after 6 months was $70 \%$ and $50.8 \%$, respectively. ${ }^{23,24}$

\section{Our technique for perioral and lip restoration in elderly women}

Selection of patients is a critical issue to ensure a satisfying aesthetic outcome. Medical history is important in 

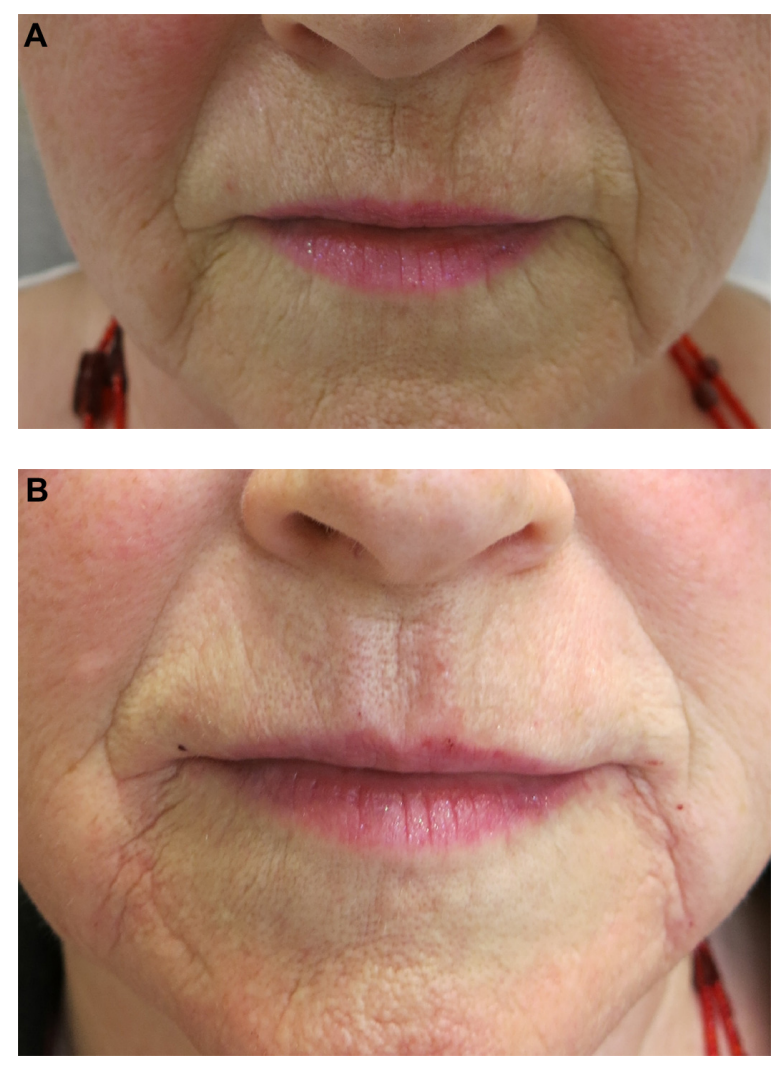

Figure 6 A 68-year-old woman with flattening of Cupid's bow, thinning of white rolls, perioral fine lines, and marionette lines.

Notes: (A) Before treatment lip fullness scale 0 (upper lip) and I (lower lip); marionette line grading scale 4 (left side) and 3 (right side). (B) After treatment with hyaluronic filler showing restoration of upper lip vermillion borders and philtrum collumelas by $\mathrm{I} \mathrm{mL}$ Juvederm ultrasmile and marionette lines by $2 \mathrm{~mL}$ Belotero basic. Lip fullness scale I (for upper lip; lower lip left untreated) and marionette line grading scale I (for both sides). Asymmetries have been corrected.

the sense of allergies, bleeding disorders, neurologic or autoimmune diseases, immunodeficiencies, or iatrogenic immunosuppression. Body dysmorphic disorders are not limited to younger patients. Such subjects will be inappropriate for filler injections. Scars and history of facial surgery have to be taken into account. Medications and over the counter drugs should be recorded..$^{25}$

The facial mimics are studied in rest and in motion. With increasing age facial asymmetries will become more prominent. The dental status is important. The findings and the treatment options should be discussed with the patient. The mirror and camera are the most important tools to define with the patient what should be modified to obtain a better appearance.

We included females older than 49 years of age $(n=57)$ with a mean age of $59.2 \pm 7.9$ years (age range 50 to 84 years). A total of 199 procedures were performed. The average follow-up was $38 \pm 11.5$ months.

We used only monophasic HA dermal fillers (Belotero, Glytone, or Juvederm) with 27 or 30 gauge needles.
The average amount of filler used per session was $1.6 \mathrm{~mL}$. Botulinum toxin A (Vistabel, Allergan; Bocouture, Merz) was diluted in physiological sodium chloride solution according to the manufacturer's recommendation. The median amount of botulinum toxin A units (Botox units) in the perioral area was $12 \pm 8$ units.

The position of the upper lip is modified by the nasolabial fold and the cheek fat pads. A minor lift of the upper lip with an improved show of the wet roll is possible by liquid lift of the cheeks (Figure 2). Very thin lips, however, will not benefit from this technique.

Augmentation by filler along the vermillion border (white roll) attenuates the convexity of this area and can improve perioral fine wrinkling (Figure 3). Soft filler with a lower stiffness is preferred even if the durability is more limited. Stiffer fillers would impair the delicate motion of the lips when speaking, singing, or smiling. Although injections of small amounts of botulinum toxin A are used to improve perioral lines in younger and middle aged females, we would not recommend this method for elderly subjects. Intrinsic and extrinsic aging eventually causes lines in rest that cannot be corrected by botulinum toxin.

Loss of volume of the upper lips is often associated with flattening of the vermillion border and partial loss of Cupid's bow. Subdermal injection of filler along the philtrum columns by threading technique improves not only the three dimensional appearance of the philtrum but Cupid's bow as well (Figures 3-5).

Deep fat injection of the upper lip into the wet roll is a method to volumize and to reshape. In case of advanced bone resorption or dental problems and loose connective tissue, advanced volumizing may lead to an undeserved ptosis (duckbill look) and loss of fine lip motion. In such cases, plastic surgery and dental restoration may be more appropriate.

The downward turn of the corners of the mouth can be seen in subjects of various ages. Whereas in younger individuals the strength of the platysma and depressor anguli oris is responsible and can be corrected by botulinum toxin injections, this is rarely the case in elderly women. ${ }^{26,27}$ Ptosis, loss of elasticity, repetitive facial expression, gravity, and extrinsic aging contribute to the downward turn which eventually results in melomental folds. These folds are associated with sadness and older age. Their negative appearance may be further increased by loss of volume in the lateral parts of lower lip. When the corner of the mouth is stretched laterally, a convex curvature of the wet roll becomes obvious (Figure 6). This is obviously due to partial loss of superficial fat layer. 
Deep fat augmentation by filler injection into the wet roll will volumize and reshape the lower lips and elevate the corners of the mouth. This will also reduce the depth of the melomental fold. In case of grade $\geq 3$ of melolabial folds, serial punctures or threading along the fold will be necessary to obtain a good outcome. Only in patients with a strong platysma, small amounts of botulinum toxin A injections into the anterior part of the platysma and close to the mandibular insertion point of the depressor anguli oris will contribute to a lift of the corner of the mouth. ${ }^{26}$ Injections need to be placed superficially because of the particular muscular anatomy. ${ }^{28}$ The chin crease can be improved by deep filler placement. In cases of poppy chin, the procedure may be combined with injections of 5-8 units of botulinum toxin A (Botox units).

The satisfaction with perioral rejuvenation in elderly females was high; $96.5 \%$ of the females were satisfied or highly satisfied. Adverse effects were mild and temporary. Pain during injection was reduced by cold compresses before and after the procedure. Bruising was the most common (16.1\%) adverse effect after rejuvenation. Slight asymmetry was seen in $0.5 \%$ of cases. We observed no case of herpes reactivation or bacterial infection.

\section{Conclusion}

Facial aging is accompanied by perioral hard and soft tissue changes leading to wrinkles, folds, and loss of contour and volume of the lips. This becomes more pronounced in elderly subjects. With individually tailored filler injection techniques, possibly in conjunction with low dose botulinum toxin, a marked improvement of appearance is realistic. Patients after dental restoration will also benefit from the rejuvenation of perioral soft tissue.

\section{Disclosure}

$\mathrm{U}$ Wollina received honoraria for lectures and courses by Allergan and Merz.

\section{References}

1. Klein AW. In search of the perfect lip: 2005. Dermatol Surg. 2005;31(11 Pt 2):1599-1603.

2. Leveque JL, Goubanova E. Influence of age on the lips and perioral skin. Dermatology. 2004;208(4):307-313.

3. Desai S, Upadhyay M, Nanda R. Dynamic smile analysis: changes with age. Am J Orthod Dentofacial Orthop. 2009;136(3):310. e1-e10.

4. Trookman NS, Rizer RL, Ford R, Mehta R, Gotz V. Clinical assessment of a combination lip treatment to restore moisturization and fullness. J Clin Aesthet Dermatol. 2009;2(12):44-48.

5. Trookman NS, Rizer RL, Ford R, Ho E, Gotz V. Immediate and longterm clinical benefits of a topical treatment for facial lines and wrinkles. J Clin Aesthet Dermatol. 2009;2(3):38-43.
6. Frese C, Staehle HJ, Wolff D. The assessment of dentofacial esthetics in restorative dentistry: a review of the literature. $J$ Am Dent Assoc. 2012;143(5):461-466.

7. Niamtu J III. Perioral soft-tissue rejuvenation techniques to enhance esthetic restorative dentistry. Compend Contin Educ Dent. 2003;24(11): 811-812, 814, 816-818.

8. Pessa JE, Slice DE, Hanz KR, Broadbent TH Jr, Rohrich RJ. Aging and the shape of the mandible. Plast Reconstr Surg. 2008;121(1):196-200.

9. Shaw RB Jr, Katzel EB, Koltz PF, Kahn DM, Girotto JA, Langstein HN. Aging of the mandible and its aesthetic implications. Plast Reconstr Surg. 2010;125(1):332-342.

10. Pendergast PM. Anatomy of the face and neck. In: Shiffman MA, Di Guiseppe A, editors. Cosmetic Surgery. Berlin-Heidelberg: SpringerVerlag; 2012:29-45.

11. Rohrich RJ, Pessa JE. The fat compartments of the face: anatomy and clinical implications for cosmetic surgery. Plast Reconstr Surg. 2007;119(7):2219-2227.

12. Rohrich RJ, Pessa JE. The anatomy and clinical implications of perioral submuscular fat. Plast Reconstr Surg. 2009;124(1):266-271.

13. Sullivan PK, Hoy EA, Mehan V, Singer DP. An anatomical evaluation and surgical approach to the perioral mound in facial rejuvenation. Plast Reconstr Surg. 2010;126(4):1333-1340.

14. Gierloff M, Stöhring C, Buder T, Wiltfang J. The subcutaneous fat compartments in relation to aesthetically important facial folds and rhytides. J Plast Reconstr Aesthet Surg. 2012;65(10):1292-1297.

15. Garcia de Mitchell CA, Pessa JE, Schaverien MV, Rohrich RJ. The philtrum: anatomical observations from a new perspective. Plast Reconstr Surg. 2008;122(6):1756-1760.

16. Carruthers A, Carruthers J, Hardas B, et al. A validated lip fullness grading scale. Dermatol Surg. 2008;34(Suppl 2):S161-S166.

17. Carruthers A, Carruthers J, Hardas B, et al. A validated grading scale for Marionette lines. Dermatol Surg. 2008;34(Suppl 2):S167-S172.

18. Wollina U, Goldman A. Hyaluronic acid dermal fillers: safety and efficacy for the treatment of wrinkles, aging skin, body sculpturing and medical conditions. Clin Med Rev Therapeutics. 2011;3:doi:10.4137/ CMRT.S6928.

19. Alam M, Gladstone H, Kramer EM, et al; American Society for Dermatologic Surgery. ASDS guidelines of care: injectable fillers. Dermatol Surg. 2008;34(Suppl 1):S115-S148.

20. Rzany B, Becker-Wegerich P, Bachmann F, Erdmann R, Wollina U. Hyaluronidase in the correction of hyaluronic acid-based fillers: a review and a recommendation for use. J Cosmet Dermatol. 2009;8(4): 317-323.

21. Santoro S, Russo S, Argenzio V, Borzacchiello A. Rheological properties of cross-linked hyaluronic acid dermal fillers. $J$ Appl Biomater Biomech. 2011;9(2):127-136.

22. Fagien S, Maas C, Murphy DK, et al; Juvéderm Lips Study Group. Juvederm ultra for lip enhancement: an open-label, multicenter study. Aesthet Surg J. 2013;33(3):414-420.

23. Glogau RG, Bank D, Brandt F, et al. A randomized, evaluator-blinded, controlled study of the effectiveness and safety of small gel particle hyaluronic acid for lip augmentation. Dermatol Surg. 2012;38(7 Pt 2): $1180-1192$.

24. Bosniak S, Cantisano-Zilkha M, Glavas IP. Nonanimal stabilized hyaluronic acid for lip augmentation and facial rhytid ablation. Arch Facial Plast Surg. 2004;6(6):379-383.

25. Wollina U, Goldman A, Naoum C. Side effects in aesthetic medicine. Spectrum, management and avoidance. Hautarzt. 2013;64(3):155-162. German.

26. Goldman A, Wollina U. Elevation of the corner of the mouth using botulinum toxin type a. J Cutan Aesthet Surg. 2010;3(3):145-150.

27. Wollina U, Payne CR. Aging well - the role of minimally invasive aesthetic dermatological procedures in women over 65. $J$ Cosmet Dermatol. 2010;9(1):50-58.

28. Wollina U, Konrad H. Managing adverse events associated with botulinum toxin type A: a focus on cosmetic procedures. Am J Clin Dermatol. 2005;6(3):141-150. 
Clinical Interventions in Aging

\section{Publish your work in this journal}

Clinical Interventions in Aging is an international, peer-reviewed journal focusing on evidence-based reports on the value or lack thereof of treatments intended to prevent or delay the onset of maladaptive correlates of aging in human beings. This journal is indexed on PubMed Central, MedLine, the American Chemical Society's 'Chemical Abstracts Ser-

\section{Dovepress}

Submit your manuscript here: http://www.dovepress.com/clinical-interventions-in-aging-journa

vice' (CAS), Scopus and the Elsevier Bibliographic databases. The manuscript management system is completely online and includes a very quick and fair peer-review system, which is all easy to use. Visit http://www.dovepress.com/testimonials.php to read real quotes from published authors. 